\title{
Wide-Bandwidth Thru-Reflect-Line
}

\section{Calibration for Empty Substrate Integrated}

\section{Coaxial Line with GCPW Transitions}

Authors: Marcos D. Fernandez, José A. Ballesteros, Juan A. Martinez, Juan Jose de Dios, Angel Belenguer

Address: all the authors are together in Departamento de Ingeniería Eléctrica, Electrónica, Automática y Comunicaciones, Universidad de Castilla-La Mancha, Escuela Politécnica de Cuenca, Campus Universitario, 16071-Cuenca (Spain)

Corresponding author: Marcos.Fernandez@uclm.es

Keywords: Thru-reflect-line, grounded coplanar (GCPW), calibration, empty substrateintegrated coaxial line (ESICL).

Abstract: Empty coaxial structures built with printed circuit boards have low radiation, low losses, high quality factor and non-dispersive features. The fully integration of empty substrate-integrated coaxial line (ESICL) in a planar substrate is nowadays a fact thanks to a grounded coplanar transition. To properly characterize and measure this new ESICL family of devices, a low cost and easy to manufacture thru-reflect-line calibration kit is proposed to de-embed not only the connectors and feeding lines, but also the ESICL transitions. 
This is the pre-peer reviewed version of the following article: Fernandez, MD, Ballesteros, JA, Martinez, JA, de Dios, JJ, Belenguer, A. Wide-bandwidth thru-reflect-line calibration for empty substrate-integrated coaxial line with grounded coplanar transitions. Microw Opt Technol Lett. 2019; 61: 292- 296, which has been published in final form at https://doi.org/10.1002/mop.31591. This article may be used for non-commercial purposes in accordance with Wiley Terms and Conditions for Use of Self-Archived Versions

\section{INTRODUCTION}

Substrate Integrated Circuits (SIC) are becoming most important every day due to their good performance characteristics (losses and quality factor) ${ }^{1}$. One of the technologies that take profit of this achievements is the Substrate Integrated Coaxial Line (SICL); these lines have single mode propagation, non-dispersion and low radiation, and therefore are suitable for wide bandwidth applications with low losses ${ }^{2}$. Recently, a new advance has been developed regarding this kind of lines with the Empty Substrate Integrated Coaxial Line (ESICL) presented in $^{3}$ in 2015, which is a novel structure that can be entirely fabricated with standard dielectric substrate layers by using exclusively Printed Circuit Board (PCB) standard manufacturing procedures; ESICL shows low cost, low losses, non-dispersion, immunity to interferences and cross-talk, etc.

Recently, some devices have been developed using ESICL: transition to grounded coplanar lines $(\mathrm{GCPW})^{3}$, a wideband bandpass filter ${ }^{3}$ and a high-Q narrow bandwidth bandpass filter ${ }^{4}$. At the same time, specific analysis techniques (BI-RME, FEM) for ESICL have also been carried out, which allow the full-wave analysis and design of ESICL devices ${ }^{1}$.

ESICL is built up by piling conventional substrate layers ${ }^{3}$. The general topology can be observed in Figure 1; it is composed of five separated PCB layers accordingly aligned and metalized to generate a suspended rectangular conductor within an empty guide. With the available transition GCPW-ESICL, it has been possible to integrate a dielectricless TEM line in a planar substrate. Devices implemented in ESICL can be manufactured quite easily and would achieve very high quality responses and low losses, with performance only comparable to Empty Substrate Integrated Waveguide (ESIW) devices and much better than the rest of conventional planar lines or $\mathrm{SICs}^{1}$. 
This is the pre-peer reviewed version of the following article: Fernandez, MD, Ballesteros, JA, Martinez, JA, de Dios, JJ, Belenguer, A. Wide-bandwidth thru-reflect-line calibration for empty substrate-integrated coaxial line with grounded coplanar transitions. Microw Opt Technol Lett. 2019; 61: 292- 296, which has been published in final form at https://doi.org/10.1002/mop.31591. This article may be used for non-commercial purposes in accordance with Wiley Terms and Conditions for Use of Self-Archived Versions

\section{DESIGN AND MANUFACTURING OF THE TRL CALIBRATION KIT FOR ESICL}

When an ESICL device is measured, most of the mismatch loss is due to the transition, together with the connectors and their solders. If the measurements are taken using a test fixture, a standard thu-reflect-line (TRL) calibration procedure ${ }^{5}$ can be applied to de-embed the connectors, so that the reference planes for the measurements are then transferred to the input and output coplanar lines. Nevertheless, there still remains losses due to the coplanar to ESICL transition, which can even mask the real response of the ESICL device alone.

In other planar technologies, like ESIW, Air-Filled Substrate Integrated Waveguide (AFSIW) or Substrate Integrated Waveguides (SIW) with similar questions regarding the accuracy of the measurements, calibration kits were designed and implemented to de-embed not only the connectors and the input line, but also the transition, so that the measurements only show the response of the real device ${ }^{6,7,8}$. Then, accordingly to that procedure, in this paper a specific thrureflect-line (TRL) calibration kit for GCPW-ESICL is presented that allows the de-embedding of the connectors, the coplanar line and the transition to the ESICL device. Additional advantages of this kit are its low cost, as it can be manufactured with standard machinery for planar circuits, its accuracy in correcting all deviations due to the elements between the network analyzer and the real ESICL device, as well as its wide frequency margin of operation, given that it is intended for bands among $2 \mathrm{GHz}$ and $18 \mathrm{GHz}$ (bands $\mathrm{S}, \mathrm{C}, \mathrm{X}, \mathrm{Ku}$ ).

The designed TRL calibration kit for ESICL consists of four standards (thru, short, line, longline), whose central layers are shown in Figure 2; their aim is to place the measurement reference planes at the beginning and at the end of the ESICL device. The standards have been manufactured with a Rogers $4003 \mathrm{C}$ substrate $\left(\varepsilon_{r}=3.55,0.813 \mathrm{~mm}\right.$ thickness, loss tangent $\tan \delta=$ $0.0027,17.5 \mu \mathrm{m}$ of copper metalization) to generate a coaxial line, which presents a width of $w_{\text {coax }}=6 \mathrm{~mm}$ with an inner conductor of width $w_{i n}=1.817 \mathrm{~mm}$. All the manufactured standards incorporate, before the ESICL specific circuit, a socket for a $\mathrm{K}$ connector, a section of GCPW 
This is the pre-peer reviewed version of the following article: Fernandez, MD, Ballesteros, JA, Martinez, JA, de Dios, JJ, Belenguer, A. Wide-bandwidth thru-reflect-line calibration for empty substrate-integrated coaxial line with grounded coplanar transitions. Microw Opt Technol Lett. 2019; 61: 292- 296, which has been published in final form at https://doi.org/10.1002/mop.31591. This article may be used for non-commercial purposes in accordance with Wiley Terms and Conditions for Use of Self-Archived Versions

line and the GCPW to ESICL transition. All these elements are included both at the input and output of the devices to be measured, and consequently, they constitute the elements to be deembedded from the measurements.

Specifically, the standards operate at the margin of frequencies of S-band, between 2-GHz and 4 GHz, C-band, between $4 \mathrm{GHz}$ and $8 \mathrm{GHz}$, X-band, between $8 \mathrm{GHz}$ and $12 \mathrm{GHz}$, and $\mathrm{Ku}$-band, between $12 \mathrm{GHz}$ and $18 \mathrm{GHz}$, and are characterized as follows:

- The reflect is ended, in this case, with a short-circuit to achieve a load of high reflectivity after a length of $25 \mathrm{~mm}$ of ESICL line.

- The thru is made up of an empty ESICL line of $50 \mathrm{~mm}$.

- The line adds an appropriate electrical length of $5.6942 \mathrm{~mm}$ between input and output ports, so the total length is $55.6942 \mathrm{~mm}$; this covers X-band and $\mathrm{Ku}-$ band.

- The long-line adds an appropriate electrical length of $18.0065 \mathrm{~mm}$ between input and output ports, so the total length is $68.0065 \mathrm{~mm}$; this, combined with the former thru, covers S-band and C-band.

The procedure to use the kit is the common in TRL calibration. Initially, the calibration kit has to be defined in the network analyzer ${ }^{9}$; then the three basic standards and the long-line are measured, so that the analyzer could correct all the systematic errors and deviations using its built-in full two-port TRL calibration function. The three basic standards correct the measurements among $8 \mathrm{GHz}$ and 18 $\mathrm{GHz}$ and the extended procedure, including the long-line, makes possible also the correction of the measurements among $2 \mathrm{GHz}$ and $8 \mathrm{GHz}$. After storing the corrections, the ESICL devices can be effectively measured with high accuracy within the operation margin.

\section{RESULTS}


This is the pre-peer reviewed version of the following article: Fernandez, MD, Ballesteros, JA, Martinez, JA, de Dios, JJ, Belenguer, A. Wide-bandwidth thru-reflect-line calibration for empty substrate-integrated coaxial line with grounded coplanar transitions. Microw Opt Technol Lett. 2019; 61: 292- 296, which has been published in final form at https://doi.org/10.1002/mop.31591. This article may be used for non-commercial purposes in accordance with Wiley Terms and Conditions for Use of Self-Archived Versions

To check the validity of the calibration kit, first the measurement and validation of the long-line is carried out. Figure 3 shows the calibrated measurement of the ESICL long-line device carried out after the calibration of the network analyzer with the three basic standards, which provides the expected results: almost complete transmission and low reflection.

Then, to prove the utility of the calibration kit using the long-line as a fourth standard to extend the measurement margin, a real useful device has been designed, manufactured and measured. It is a 5th-order Chebyshev filter centered at $13 \mathrm{GHz}$ with bandwidth of $300 \mathrm{MHz}, 0.01 \mathrm{~dB}$ of ripple and simulated quality factor of 1643 (calculated according to equations given in ${ }^{10}$ ); its layercomposition is shown in Figure 4. This filter exhibits the same topology that was presented in ${ }^{4}$.

Figure 5 shows the measured response of the ESICL filter in the margin from $2 \mathrm{GHz}$ to $18 \mathrm{GHz}$ by applying the extended calibration procedure; this plot reveals a measurement of high quality and accuracy in a wide frequency bandwidth (from bands $\mathrm{S}$ to $\mathrm{Ku}$ ), what reasserts the validity of the measurement procedure. A zoomed version of the plot can be seen at Figure 6 in the narrow designed margin from $12 \mathrm{GHz}$ to $14 \mathrm{GHz}$; it leads to a measured insertion loss of $0.98 \mathrm{~dB}$, which is very low, and provides a measured quality factor ${ }^{10}$ of 1509 , which is very high and close to the simulated one. The response of this standalone ESICL filter has been simulated using CST Studio Suite. The results of this simulation are also included in Figure 6, where it can be noticed a good agreement between measurements and simulation. This also proves the high quality of the deembedding process that the calibration kit is able to provide.

As it has been already stated, the main advantage of using this calibration kit is the high quality and accuracy of the measurements that can be achieved. To reaffirm this fact, the real effect of the calibration kit can be seen in Figure 7, where the comparison of the measurement of the long-line is done by using the standard coaxial calibration of the network analyzer and by using the new ESICL calibration kit; a difference of more than $1.4 \mathrm{~dB}$ can be observed between both measurements due to the K connectors, the sections of GCPW lines and the GCPW to ESICL transitions. A similar 
This is the pre-peer reviewed version of the following article: Fernandez, MD, Ballesteros, JA, Martinez, JA, de Dios, JJ, Belenguer, A. Wide-bandwidth thru-reflect-line calibration for empty substrate-integrated coaxial line with grounded coplanar transitions. Microw Opt Technol Lett. 2019; 61: 292- 296, which has been published in final form at https://doi.org/10.1002/mop.31591. This article may be used for non-commercial purposes in accordance with Wiley Terms and Conditions for Use of Self-Archived Versions

comparison can be seen in Figure 8 for the filter in the narrow-margin of the bandpass; a difference of $1.4 \mathrm{~dB}$ in the measurement at the central frequency is stated.

\section{CONCLUSION}

The novelty and high quality of the recent ESICL technology points to a promising development of devices designed according to their principles. So that these devices could be properly characterized, a calibration procedure is required so that connectors, input and output lines and transitions to, and from, ESICL could be de-embedded to achieve measurements of high quality and accuracy.

This paper has presented the design, manufacture and validation of a wide-bandwidth calibration kit for ESICL, which presents also the advantages of being low cost and quite easy to design and manufacture by means of standard machinery and common substrates.

As it may be expected, both basic and extended ESICL calibration procedures are much better than the standard coaxial calibration procedure of the network analyzer; losses due to connectors, coplanar lines and GCPW to ESICL transitions can be removed with the calibration kit.

Consequently, it gives measurements closer to reality, as the characterization of real devices can be achieved with higher accuracy. This is due to the fact that the effects of all the intermediate elements to insert the signal into the device and extract it from the device can be de-embedded.

The basic calibration kit presented has been used to extend the corrections of the measurements to a wider frequency margin, from $2 \mathrm{GHz}$ to $18 \mathrm{GHz}$, using for that a long-line as a fourth standard; with the extended procedure, it has been possible to successfully measure a practical ESICL device -a bandpass filter-.

The improvement regarding the simple standard coaxial calibration of the network analyzer has also been revealed to reinforce the high quality of the described wide-bandwidth calibration kit. 
This is the pre-peer reviewed version of the following article: Fernandez, MD, Ballesteros, JA, Martinez, JA, de Dios, JJ, Belenguer, A. Wide-bandwidth thru-reflect-line calibration for empty substrate-integrated coaxial line with grounded coplanar transitions. Microw Opt Technol Lett. 2019; 61: 292- 296, which has been published in final form at https://doi.org/10.1002/mop.31591. This article may be used for non-commercial purposes in accordance with Wiley Terms and Conditions for Use of Self-Archived Versions

\section{ACKNOWLEDGMENT}

This work was supported by the Ministerio de Ciencia e Innovación, Spanish Government, under Project TEC2016-75934-C4-3-R. 
This is the pre-peer reviewed version of the following article: Fernandez, MD, Ballesteros, JA, Martinez, JA, de Dios, JJ, Belenguer, A. Wide-bandwidth thru-reflect-line calibration for empty substrate-integrated coaxial line with grounded coplanar transitions. Microw Opt Technol Lett. 2019; 61: 292- 296, which has been published in final form at https://doi.org/10.1002/mop.31591. This article may be used for non-commercial purposes in accordance with Wiley Terms and Conditions for Use of Self-Archived Versions

\section{REFERENCES}

1. A. Belenguer, H. Esteban, A.L. Borja, and V. Boria, Empty substrate integrated waveguide technologies: a major step-forward towards realizing low-cost and low-loss microwave circuits, accepted in IEEE Microwave Magazine, 2018.

2. F. Gatti, M. Bozzi, L. Perregrini, K. Wu, and R. Bosisio, A novel substrate integrated coaxial line (SICL) for wide-band applications, in Proceedings 36th European Microwave Conference, 2006; pp. 1614-1617.

3. A. Belenguer, A.L. Borja, H. Esteban, and V. Boria, High-performance coplanar waveguide to empty substrate integrated coaxial line transition, IEEE Transactions on Microwave Theory and Techniques, 2015; vol. 63, no. 12, pp. 4027-4034.

4. A. L. Borja, A. Belenguer, H. Esteban, and V. Boria, Design and performance of a high-Q narrow bandwidth bandpass filter in empty substrate integrated coaxial line at Ku-band, IEEE Microwave and Wireless Components Letters, 2017; vol. 27, no. 11, pp. 977-979.

5. G.F. Engen and C.A. Hoer, Thru-reflect-line: an improved technique for calibrating the dual six-port automatic network analyzer, IEEE Trans. Microw. Theory Tech., 1979; vol. 27, no. 12, pp. 987-993.

6. M. Fernandez, J.A. Ballesteros, L. Martinez, H. Esteban, and Belenguer, Thru-reflect-line calibration for empty substrate integrated waveguide with microstrip transitions, Electronic Letters, 2015; vol. 51, no. 16, pp. 1274-1276.

7. F. Parment, A. Ghiotto, T.P. Vuong, J.M. Duchamp, and K. Wu, Low-loss air-filled Substrate Integrated Waveguide (SIW) band-pass filter with inductive posts, in European Microwave Conference (EuMC), 2015; pp. 761-764. 
This is the pre-peer reviewed version of the following article: Fernandez, MD, Ballesteros, JA, Martinez, JA, de Dios, JJ, Belenguer, A. Wide-bandwidth thru-reflect-line calibration for empty substrate-integrated coaxial line with grounded coplanar transitions. Microw Opt Technol Lett. 2019; 61: 292- 296, which has been published in final form at https://doi.org/10.1002/mop.31591. This article may be used for non-commercial purposes in accordance with Wiley Terms and Conditions for Use of Self-Archived Versions

8. E. Diaz, A. Belenguer, H. Esteban, and V. Boria, Thru-reflect-line calibration for substrate integrated waveguide with tapered microstrip transitions, Electronic Letters, 2013; vol. 49, no. 2 , pp. $132-133$.

9. Anritsu, VectorStar MS4640A Series Microwave Vector Network Analyzers: Calibration and Measurement Guide, Anritsu Product Note 10410-00269, Tech. Rep., 2015.

10. J.-S. G. Hong and M.J. Lancaster, Microstrip filters for RF/microwave applications, John Wiley and Sons, 2004, vol. 167. 
This is the pre-peer reviewed version of the following article: Fernandez, MD, Ballesteros, JA, Martinez, JA, de Dios, JJ, Belenguer, A.

Wide-bandwidth thru-reflect-line calibration for empty substrate-integrated coaxial line with grounded coplanar transitions. Microw Opt

Technol Lett. 2019; 61: 292- 296, which has been published in final form at https://doi.org/10.1002/mop.31591. This article may be used for non-commercial purposes in accordance with Wiley Terms and Conditions for Use of Self-Archived Versions

\section{FIGURES AND CAPTIONS}
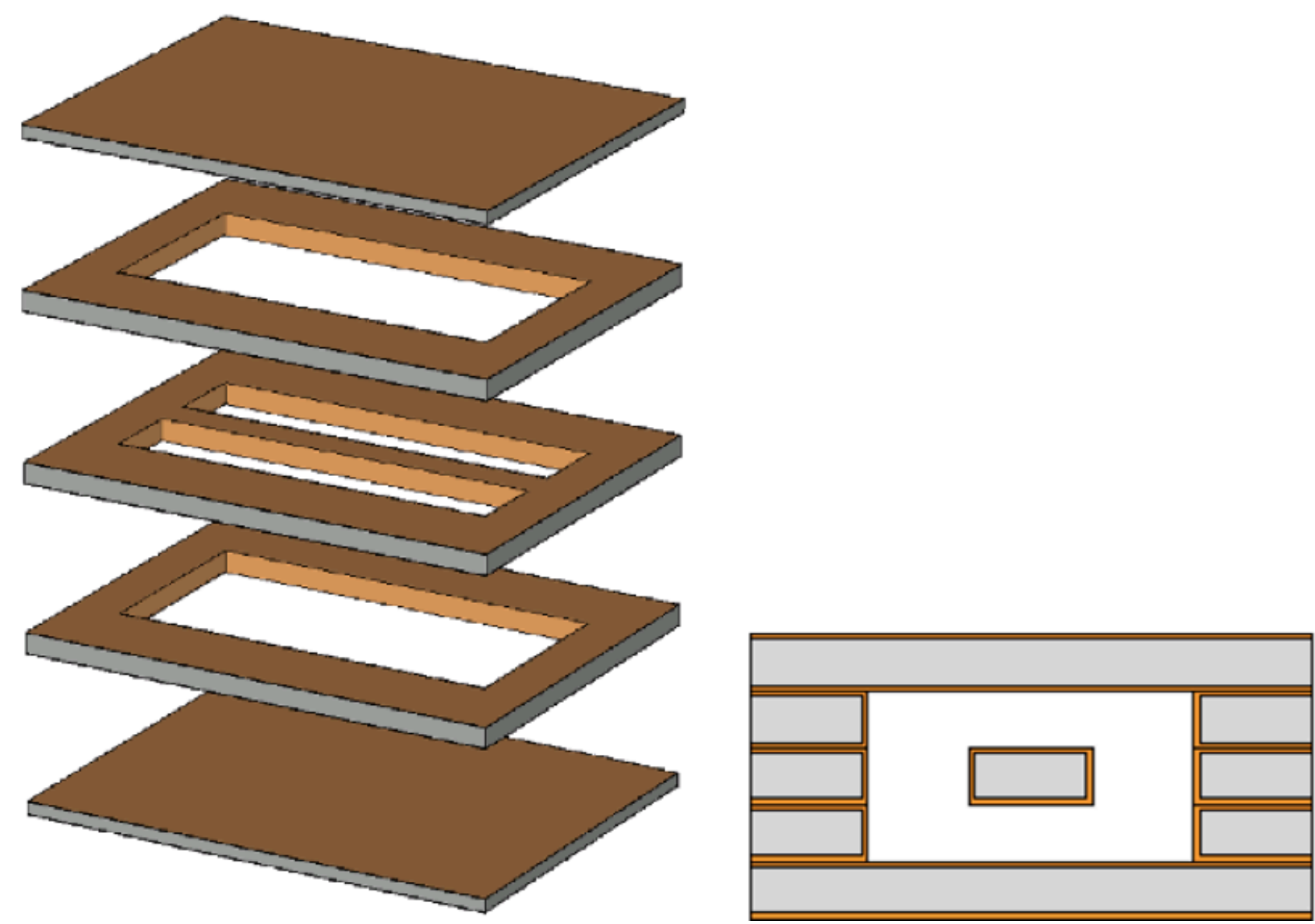

FIGURE 1 Construction of a typical ESICL structure ${ }^{3}$ : (left) separated layers; (right) cross-section. 
This is the pre-peer reviewed version of the following article: Fernandez, MD, Ballesteros, JA, Martinez, JA, de Dios, JJ, Belenguer, A. Wide-bandwidth thru-reflect-line calibration for empty substrate-integrated coaxial line with grounded coplanar transitions. Microw Opt Technol Lett. 2019; 61: 292- 296, which has been published in final form at https://doi.org/10.1002/mop.31591. This article may be used for non-commercial purposes in accordance with Wiley Terms and Conditions for Use of Self-Archived Versions

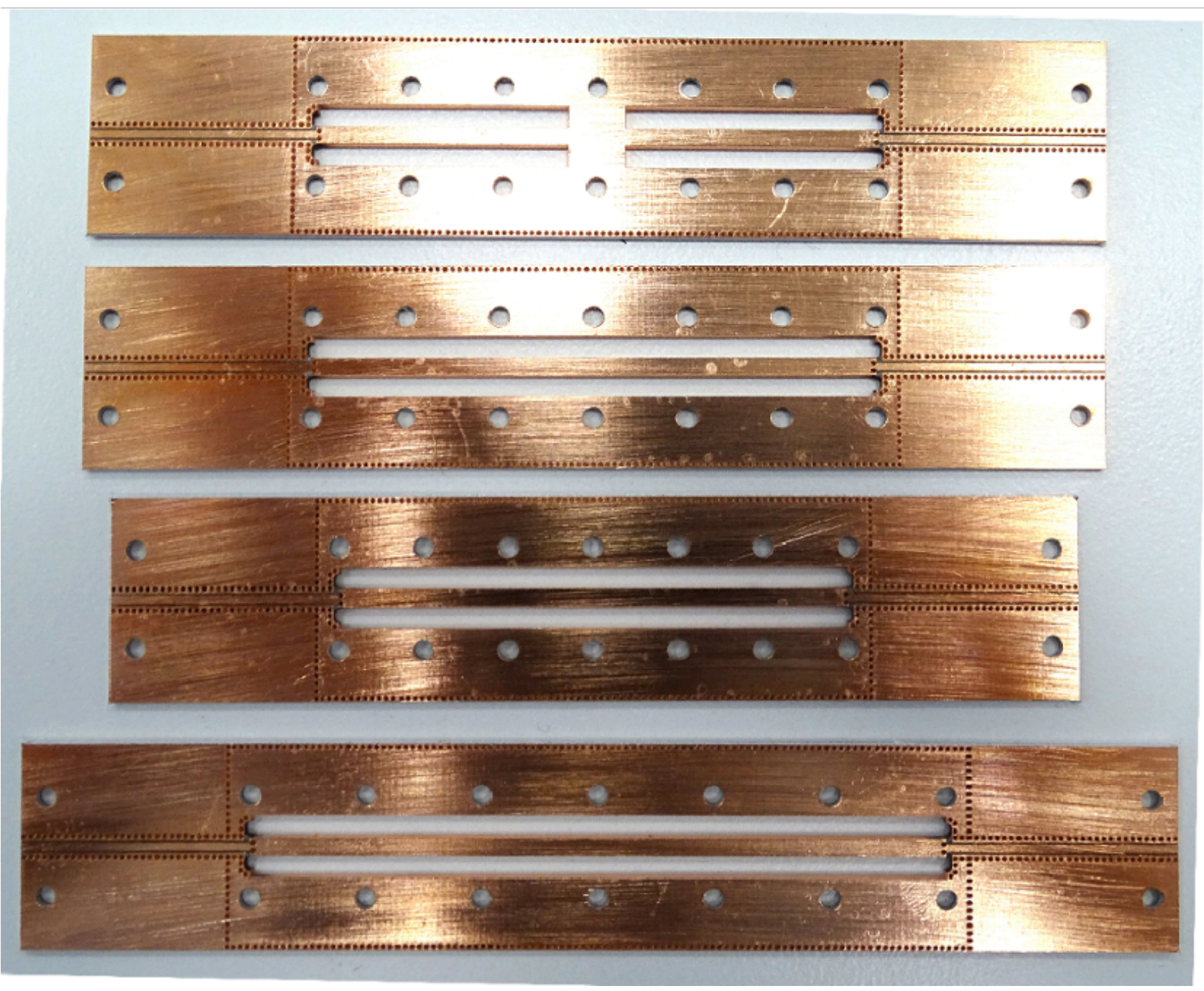

FIGURE 2 Central layer of the manufactured circuits, from top to bottom: short, line, thru, longline. 
This is the pre-peer reviewed version of the following article: Fernandez, MD, Ballesteros, JA, Martinez, JA, de Dios, JJ, Belenguer, A. Wide-bandwidth thru-reflect-line calibration for empty substrate-integrated coaxial line with grounded coplanar transitions. Microw Opt Technol Lett. 2019; 61: 292- 296, which has been published in final form at https://doi.org/10.1002/mop.31591. This article may be used for non-commercial purposes in accordance with Wiley Terms and Conditions for Use of Self-Archived Versions

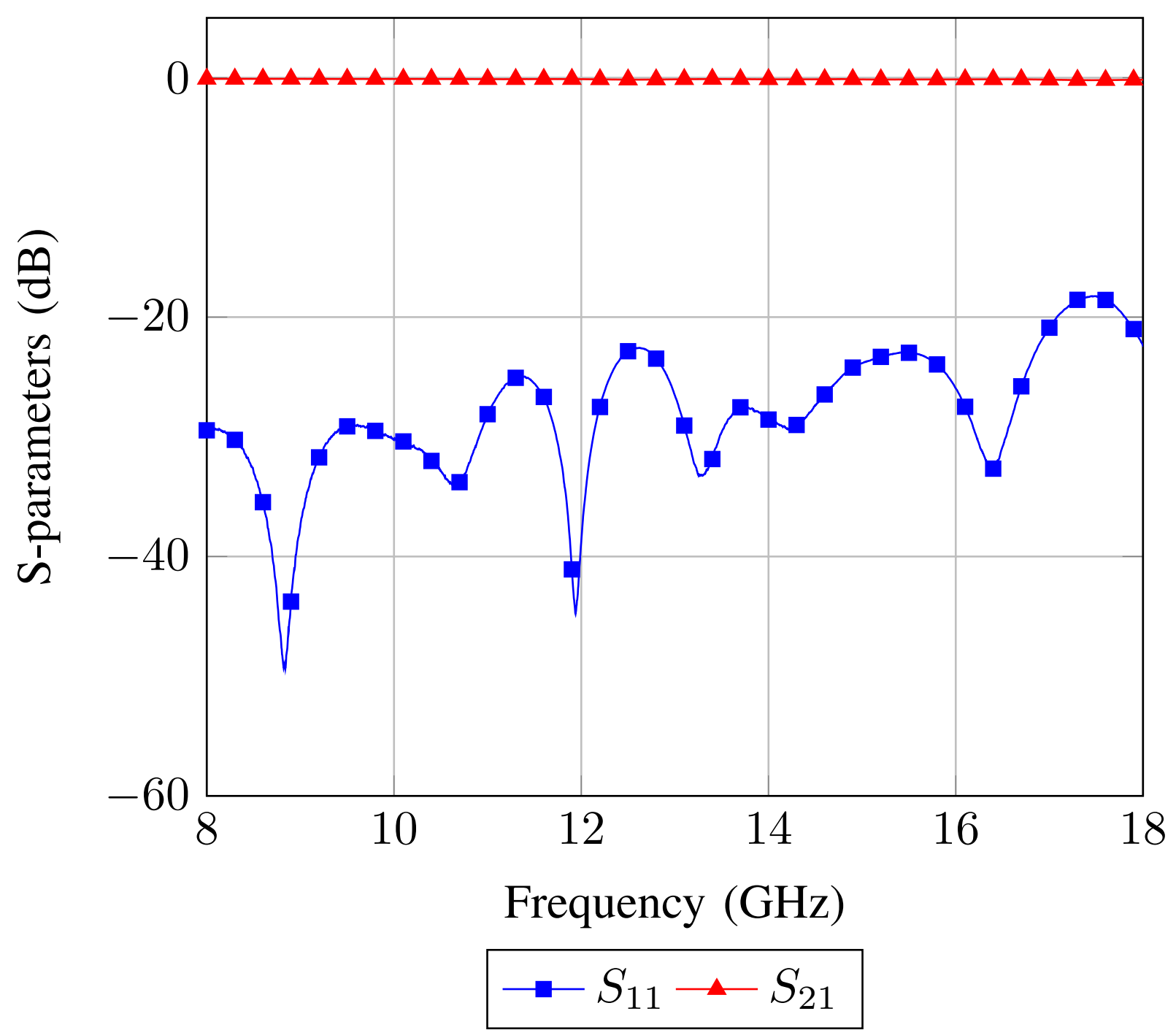

FIGURE 3 Measurement of long line with the basic 3-standards ESICL calibration. 
This is the pre-peer reviewed version of the following article: Fernandez, MD, Ballesteros, JA, Martinez, JA, de Dios, JJ, Belenguer, A. Wide-bandwidth thru-reflect-line calibration for empty substrate-integrated coaxial line with grounded coplanar transitions. Microw Opt Technol Lett. 2019; 61: 292- 296, which has been published in final form at https://doi.org/10.1002/mop.31591. This article may be used for non-commercial purposes in accordance with Wiley Terms and Conditions for Use of Self-Archived Versions

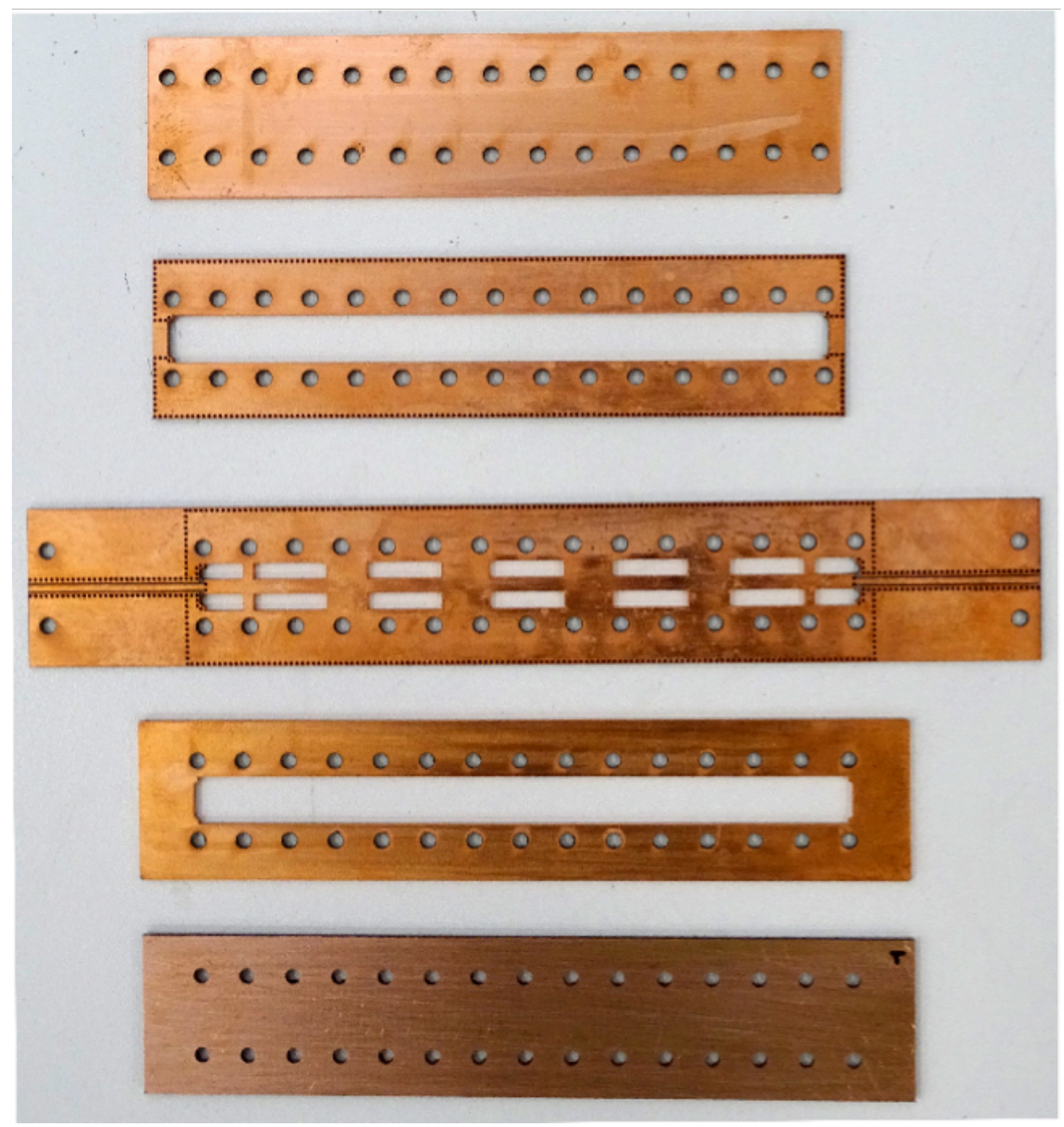

FIGURE 4 ESICL filter to be measured. 
This is the pre-peer reviewed version of the following article: Fernandez, MD, Ballesteros, JA, Martinez, JA, de Dios, JJ, Belenguer, A. Wide-bandwidth thru-reflect-line calibration for empty substrate-integrated coaxial line with grounded coplanar transitions. Microw Opt Technol Lett. 2019; 61: 292- 296, which has been published in final form at https://doi.org/10.1002/mop.31591. This article may be used for non-commercial purposes in accordance with Wiley Terms and Conditions for Use of Self-Archived Versions

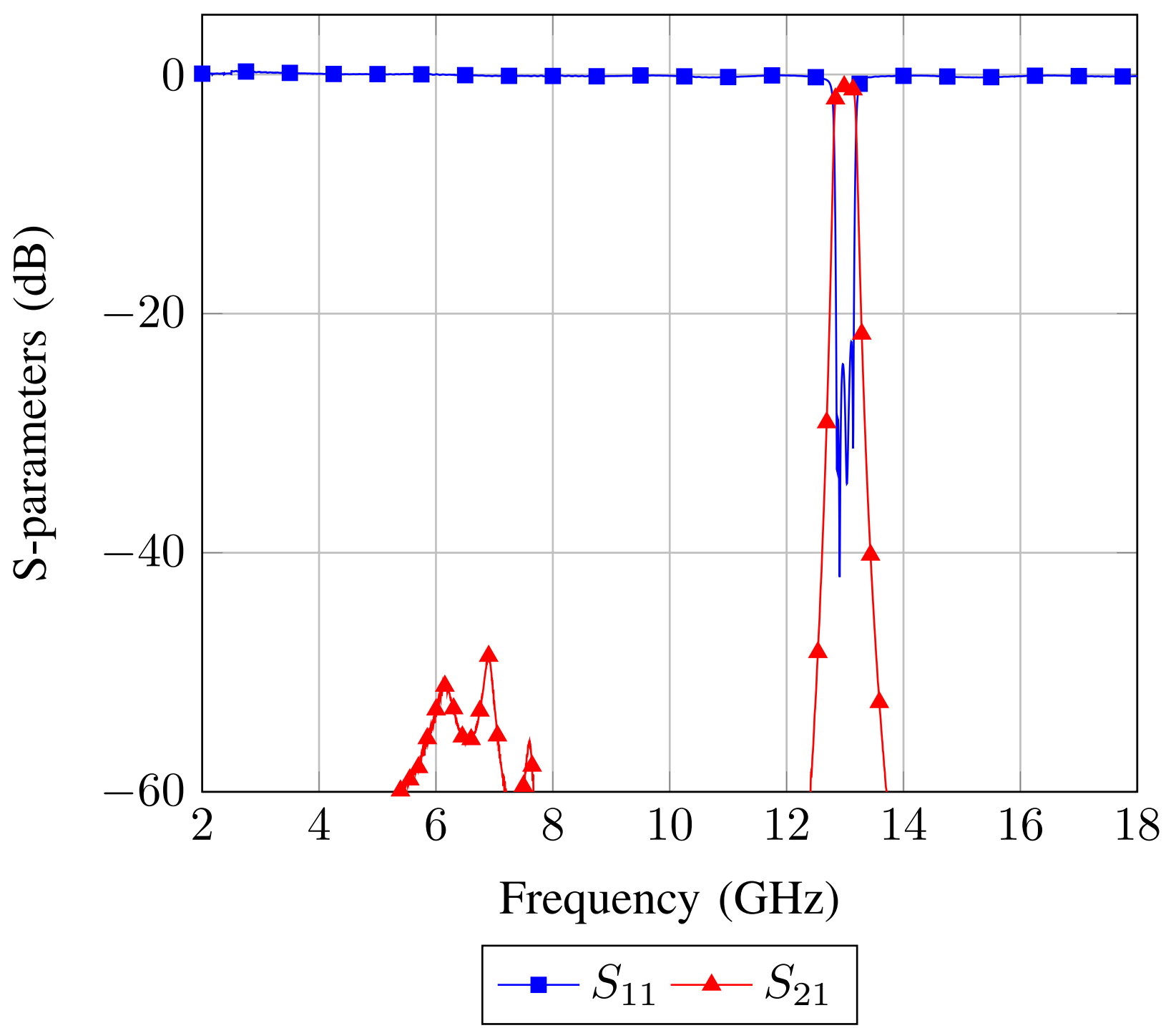

FIGURE 5 Measurement of filter with the extended 4-standards ESICL calibration in the full$\operatorname{margin}(2-18 \mathrm{GHz})$. 
This is the pre-peer reviewed version of the following article: Fernandez, MD, Ballesteros, JA, Martinez, JA, de Dios, JJ, Belenguer, A. Wide-bandwidth thru-reflect-line calibration for empty substrate-integrated coaxial line with grounded coplanar transitions. Microw Opt Technol Lett. 2019; 61: 292- 296, which has been published in final form at https://doi.org/10.1002/mop.31591. This article may be used for non-commercial purposes in accordance with Wiley Terms and Conditions for Use of Self-Archived Versions

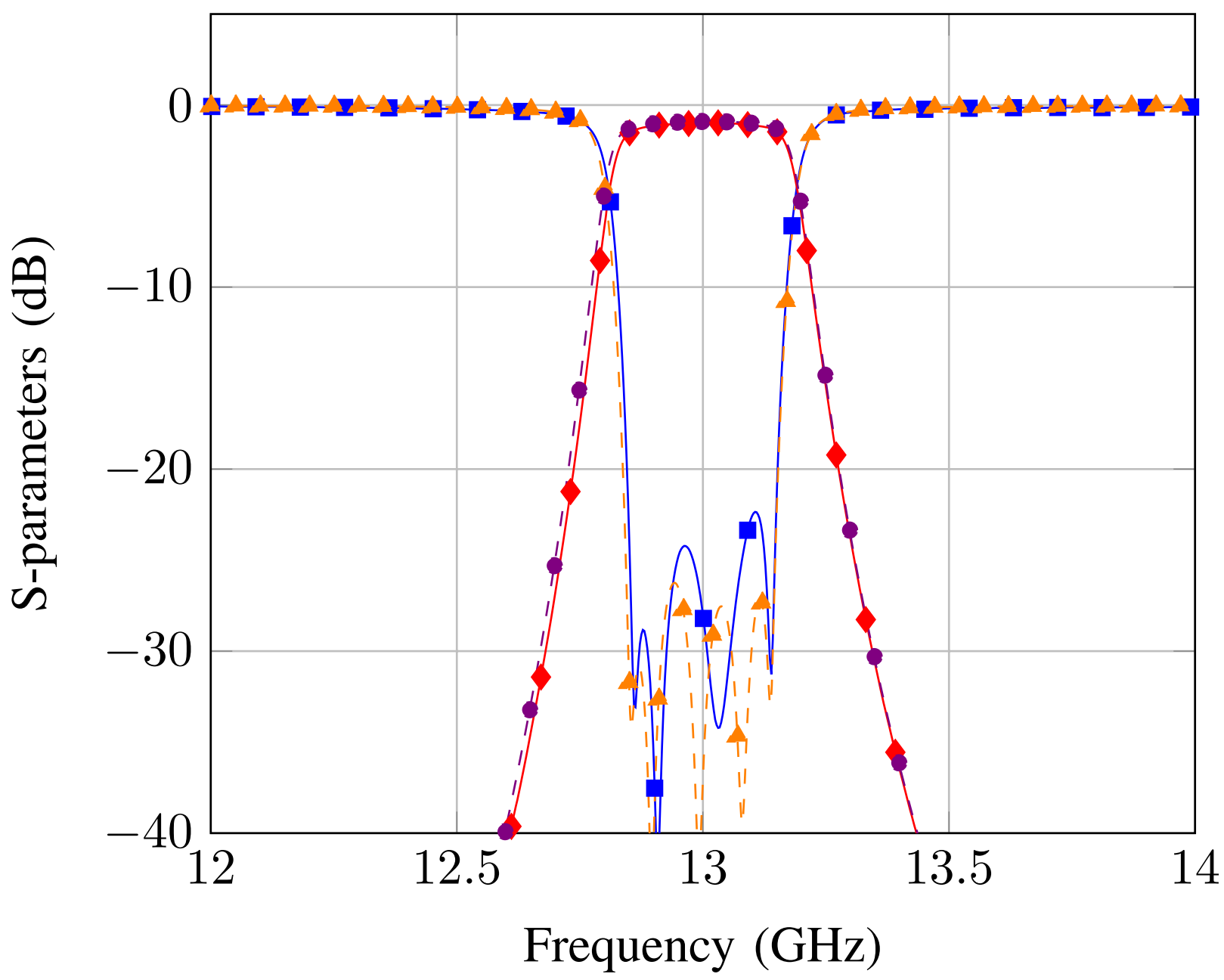

$\multimap S_{11}$ meas. $--S_{11}$ sim. $\multimap S_{21}$ meas. $--S_{21}$ sim.

FIGURE 6 Comparison of simulated and measured filter with ESICL calibration in the range from $12 \mathrm{GHz}$ to $14 \mathrm{GHz}$. 
This is the pre-peer reviewed version of the following article: Fernandez, MD, Ballesteros, JA, Martinez, JA, de Dios, JJ, Belenguer, A. Wide-bandwidth thru-reflect-line calibration for empty substrate-integrated coaxial line with grounded coplanar transitions. Microw Opt Technol Lett. 2019; 61: 292- 296, which has been published in final form at https://doi.org/10.1002/mop.31591. This article may be used for non-commercial purposes in accordance with Wiley Terms and Conditions for Use of Self-Archived Versions

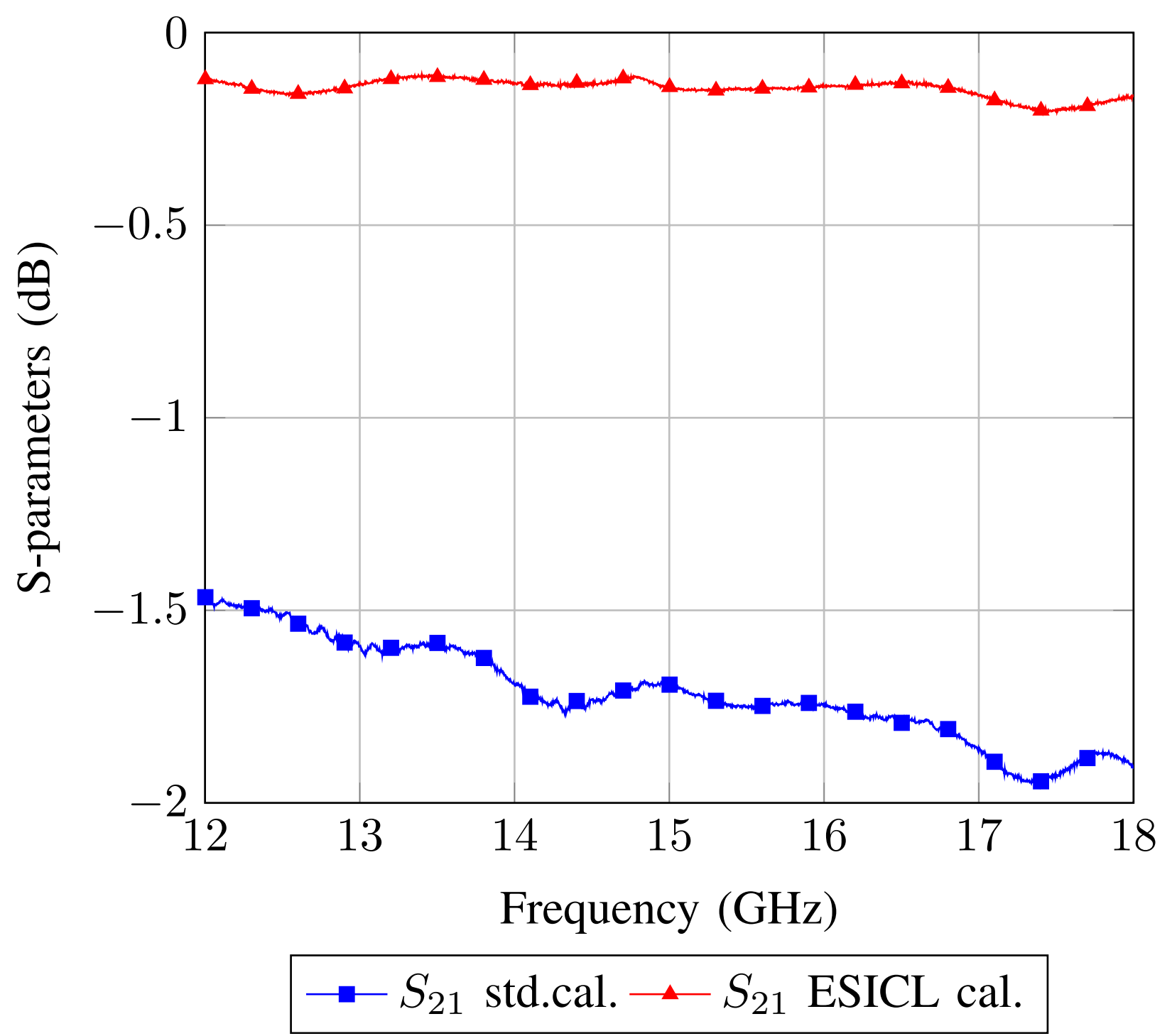

FIGURE 7 Comparison between ESICL calibration kit and standard network analyzer calibration procedure: correction of the de-embedding in the long-line. 
This is the pre-peer reviewed version of the following article: Fernandez, MD, Ballesteros, JA, Martinez, JA, de Dios, JJ, Belenguer, A. Wide-bandwidth thru-reflect-line calibration for empty substrate-integrated coaxial line with grounded coplanar transitions. Microw Opt Technol Lett. 2019; 61: 292- 296, which has been published in final form at https://doi.org/10.1002/mop.31591. This article may be used for non-commercial purposes in accordance with Wiley Terms and Conditions for Use of Self-Archived Versions

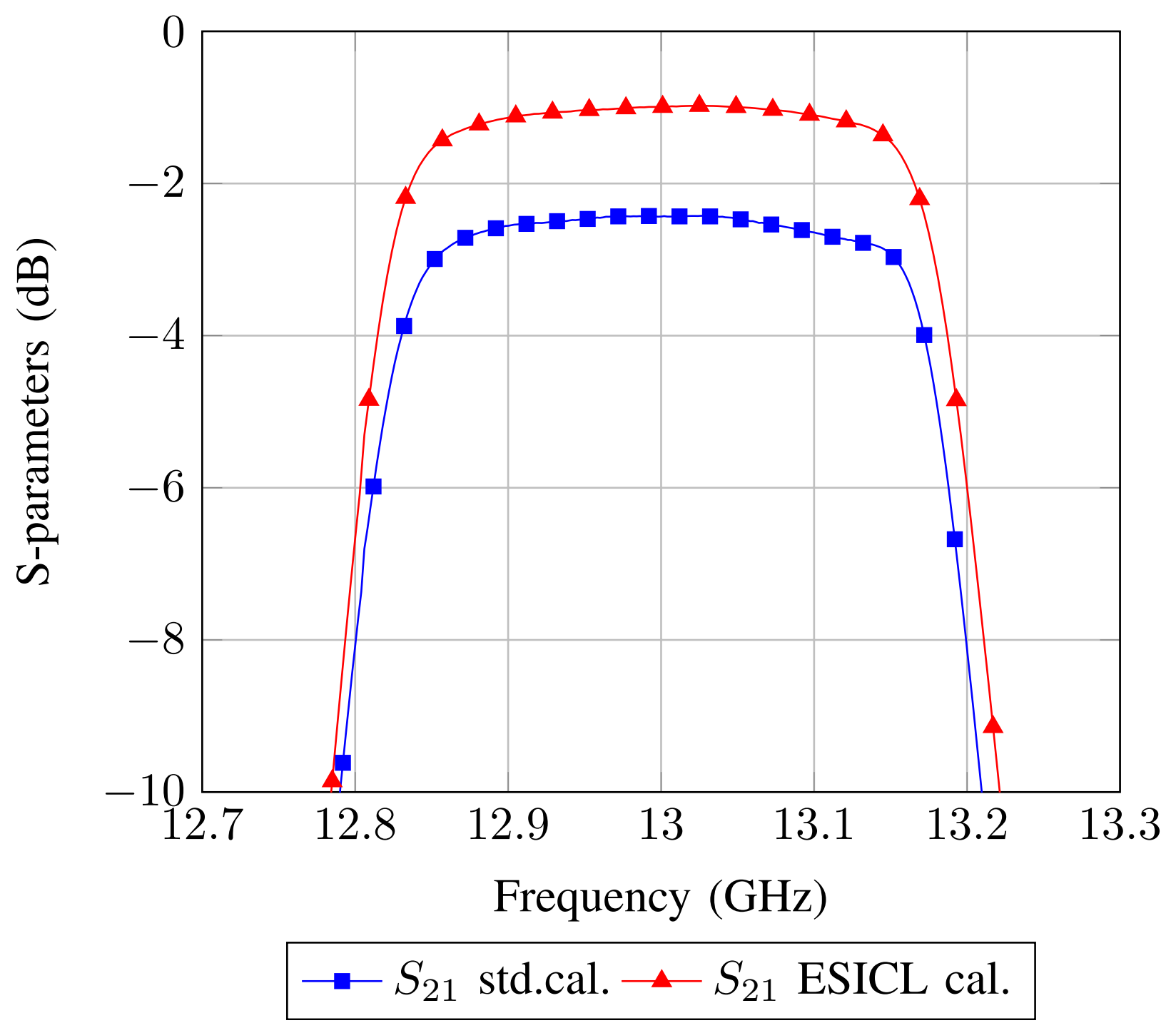

FIGURE 8 Comparison between ESICL extended calibration kit and standard network analyzer calibration procedure: correction of the de-embedding in the filter. 